\begin{tabular}{|l|l|l|l|}
\hline Editorial & W w de Herder et al. & Dik Kwekkeboom & 24:5 \\
\hline
\end{tabular}

\title{
In memoriam: Dirk J Kwekkeboom (1958-2017)
}

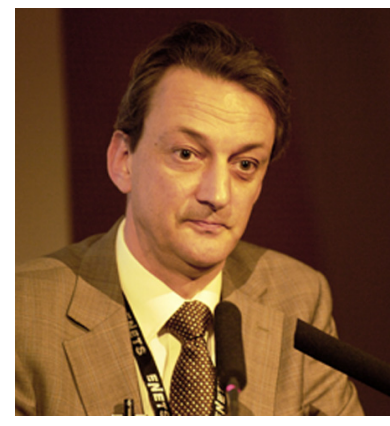

1Division of Endocrinology, Department
${ }^{2}$ Cyclotron BV, Rotterdam, Netherlands

3Department of Radiology and Nuclear Medicine, Erasmus MC, Rotterdam, Netherlands

Correspondence should be addressed to $W$ W de Herder

Email

w.w.deherder@erasmusmc.nl
Dirk J Kwekkeboom MD, widely regarded as one of Europe's foremost experts on peptide receptor radiotherapy (PRRT), passed away 8 March 2017, at the age of 58.

The publication by Tessa Brabander and colleagues in this issue of Endocrine-Related Cancer is, unfortunately, one of the last papers co-authored by Dik (Brabander et al. 2017). The total output of Dik as a (co-)author for this journal adds up to four papers, including two highly cited reviews (Kwekkeboom et al. 2010, Teunissen et al. 2011, Kamp et al. 2013, Brabander et al. 2017).

Beloved by all and affectionately known as Dik, he had just been appointed Professor of Nuclear Medicine at the Erasmus University in December 2015. Dik received his MD from the University of Amsterdam in 1985. Subsequently, he started his scientific career in the group of Steven Lamberts in the Sector of Endocrinology of the Department of Internal Medicine at the Erasmus MC, Rotterdam, the Netherlands. In 1989, he received his $\mathrm{PhD}$ on his studies on clinically nonfunctioning and gonadotroph pituitary adenomas at the Erasmus University, Rotterdam. He joined the group of Eric Krenning in the Department of Nuclear Medicine at the Erasmus MC in 1990. He would continue working in this Department for the rest of his too-short life. At the start of Dik's career, the Department was involved in the development of somatostatin receptor scintigraphy (SRS) for somatostatin receptor-bearing tumors. In 1991, Indium-111-pentetreotide was introduced for SRS, and Dik was responsible for the cost-benefit analyses. In 1992, the first PRRT using Indium-111-pentetreotide was performed. Yttrium-90-labelled somatostatin analogues were subsequently introduced. From 2000 onwards, Lutetium-177-DOTA-octreotate was mainly used. As head of the Lu-PRRT team, Dik was involved in the Lutetium177-DOTA-octreotate PRRT of more than 1500 patients. These patients were referred from all over the world.

Over the years, Dik was responsible for the training of nuclear medicine physicians. His excellent educational skills also resulted in Dik being invited to many national and international postgraduate and educational courses. Dik was a member of the Advisory Boards of both the European Neuroendocrine Tumor Society (ENETS) and the North American Neuroendocrine Tumors Society (NANETS). He was involved in almost all guidelines and/ or state-of-the-art papers in the PRRT field. He was also the head of a very active research group. The scientific output of Dik is tremendous and of great importance. It adds up to approximately 31 original papers, 33 reviews and 8 guidelines co-authored by Dik on the subject of PRRT. Dik's approach to scientific conduct was usually accompanied by sharp remarks and by a good joke. He used humor to mentor and guide.

Dik was a lover of classical music. He rarely missed the world-famous Gergiev Festival of the Rotterdam Philharmonic Orchestra. He loved reading books and was the proud owner of the collection of Russian literature amongst many other books by renowned international writers. Dik loved good food and especially good wine. He was a true connoisseur.

Dik was predeceased in 2008 by his partner Peter and in 1989 by his sister Tien. He is survived by his sisters Nelie and An, and by his brother Jaap.

Published by Bioscientifica Ltd 


\section{References}

Brabander T, van der Zwan WA, Teunissen JJM, Kam BLR, de Herder WW, Feelders RA, Krenning EP \& Kwekkeboom DJ 2017 Pitfalls in the response evaluation after peptide receptor radionuclide therapy with $\left[{ }^{177} \mathrm{Lu}-\mathrm{DOTA}{ }^{0}, \mathrm{Tyr}^{3}\right]$ octreotate. Endocrine-Related Cancer 24 243-251. (doi:10.1530/ ERC-16-0524)

Kamp K, Gumz B, Feelders RA, Kwekkeboom DJ, Kaltsas G, Costa FP \& de Herder WW 2013 Safety and efficacy of everolimus in gastrointestinal and pancreatic neuroendocrine tumors after
${ }^{177} \mathrm{Lu}-\mathrm{octreotate}$. Endocrine-Related Cancer 20 825-831. (doi:10.1530/ ERC-13-0254)

Kwekkeboom DJ, Kam BL, van Essen M, Teunissen JJ, van Eijck CH, Valkema R, de Jong M, de Herder WW \& Krenning EP 2010 Somatostatin-receptor-based imaging and therapy of gastroenteropancreatic neuroendocrine tumors. Endocrine-Related Cancer 17 R53-R73. (doi:10.1677/ERC-09-0078)

Teunissen JJ, Kwekkeboom DJ, Valkema R \& Krenning EP 2011 Nuclear medicine techniques for the imaging and treatment of neuroendocrine tumours. Endocrine-Related Cancer 18 (Supplement 1) S27-S51. (doi:10.1530/ERC-10-0282)

Received in final form 15 March 2017

Accepted 17 March 2017 